\title{
ВОЗМОЖНОСТЬ ОБИТАНИЯ ВОЗБУДИТЕЛЯ COVID- 19 В ВОДНОЙ СРЕДЕ (ОБЗОР ЛИТЕРАТУРЫ)
}

П.В. Журавлёв ${ }^{1,2}$, А.С. Калюжин ${ }^{1}$, М.А. Кулак ${ }^{1}$, Н.В.Алексанина ${ }^{1}$, М.Н. Гапон ${ }^{1}$, Т.И. Твердохлебова ${ }^{1,2}$

${ }^{1}$ ФБУН «Ростовский научно-исследовательский институт микробиологии и паразитологии» Роспотребнадзора, г. Ростов-на-Дону, Российская Федерация ${ }^{2}$ ФГБОУ ВО «Ростовский государственный медицинский университет» Минздрава России, Ростов-на-Дону, Российская Федерация

\section{POSSIBILITY OF HABITAT OF THE COVID-19 IN A WATER ENVIRONMENT (LITERATURE REVIEW)}

\author{
P.V. Zhuravlev ${ }^{1,2}$, A.S. Kalyuzhin ${ }^{1}$, M.A. Kulak ${ }^{1}$, N.V. Aleksanina ${ }^{1}$, M.N. Gapon ${ }^{1}$, \\ T.I. Tverdokhlebova ${ }^{1,2}$
}
${ }^{1}$ FBUN "Rostov Research Institute of Microbiology and Parasitology" Rospotrebnadzor, Rostov-on-Don, Russian Federation
${ }^{2}$ FGBOU HE "Rostov State Medical University" of the Ministry of Health of Russia, Rostov-on-Don, Russian Federation

Резюме. В настоящей работе представлен обзор научных данных зарубежных и российских исследователей о возможном обитании возбудителя COVID-19 в водной среде, сведений о путях распространения инфекционного агента SARS-CoV-2 и принимаемых мерах по борьбе с ним в водной среде. Показано присутствие возбудителя COVID-19 в различных объектах окружающей среды: системах водоснабжения, сточных водах, поверхностных водах. Определены методы детекции вирусных частиц SARS-CoV-2 на основе выявления штаммов других вирусов в объектах окружающей среды. Это позволило понять, что попадание вируса в экосистему происходит за счёт абсорбирования с различными фомитами. В обзоре представлены результаты работ, проведенных в ряде стран во время пандемии, подтверждающие присутствие COVID-19 в речной воде. Часть исследований указывает на устойчивость вирусных частиц, присутствующих в объектах окружающей среды, к дезинфицирующим средствам, что в свою очередь определяет актуальность углубленных исследований с позиции обеспечения санитарнопротивоэпидемического режима на станциях водоподготовки.

Ключевые слова: COVID-19, SARS-CoV-2, сточные воды, очистные сооружения, речная вода

Summary. This paper presents an overview of the scientific data of foreign and Russian researchers on the possible habitation of the pathogen COVID-19 in the aquatic environment, 
information on the ways of spreading the infectious agent SARS-CoV-2 and measures taken to combat it in the aquatic environment. The presence of the causative agent COVID-19 in various environmental objects is shown: water supply systems, wastewater, surface water. Methods for detecting SARS-CoV-2 viral particles based on the detection of strains of other viruses in environmental objects have been determined. This made it possible to understand that the entry of the virus into the ecosystem occurs due to absorption with various fomites. The review presents the results of work carried out in a number of countries during the pandemic, confirming the presence of COVID-19 in river water. Some studies indicate the resistance of viral particles present in environmental objects to disinfectants, which in turn determines the relevance of in-depth studies from the standpoint of ensuring the sanitary and anti-epidemic regime at water treatment plants.

Keywords: COVID-19, SARS-CoV-2, wastewater, treatment facilities, river water

\section{Введение.}

Коронавирусы, принадлежащие к одноимённому роду семейства Coronaviridae, широко распространены в природе. Впервые открытые ещё в 30-х годах прошлого века, до недавнего времени они были известны как возбудители тяжёлых, нередко смертельных, заболеваний среди сельскохозяйственных животных и домашних птиц.

В марте 2003 года Всемирная организация здравоохранения (ВОЗ) объявила о глобальной эпидемии так называемой «атипичной пневмонии» или тяжёлого острого респираторного синдрома (ТОРС). По данным ВОЗ, к августу 2003 г. было зарегистрировано 8098 случаев ближневосточного респираторного синдрома (SARS-CoV) с 4-11\% летальностью [1]. Это заболевание, впервые зарегистрированное в ноябре 2002 года в Южном Китае, в течение нескольких месяцев распространилось на территориях 30 государств Азии, Европы, Северной и Южной Америки, Африки и Австралии. Наибольшее количество заболевших было выявлено в Китайской Народной Республике (КНР), Сингапуре и Канаде. Распространение вируса произошло стремительно из ЮгоВосточной Азии по международным авиалиниям, что связано с коротким инкубационным периодом от 2 до 3 суток, вызванного им заболевания [1-4]. Инфицирование людей чаще происходило в госпитальных условиях. Один больной в среднем заражал трёх-четырёх контактных лиц [5].

Вспышка новой коронавирусной инфекции зарегистрирована в декабре 2019 г. в г. Ухань (провинция Хубэй, КНР) [6], хотя первые случаи были зафиксированы ещё в ноябре 2019 г. Она распространилась на другие 30 городов КНР, включая Пекин и Шанхай [7]. Инфицированные пациенты были выявлены более чем в 40 странах Азии, Америки, Европы и Австралии; в Российской Федерации - два случая. В настоящее время пандемия охватила более 200 стран, всего в мире зарегистрировано более 35 миллионов подтверждённых случаев COVID-19.

В связи с широким и быстрым распространением новой коронавирусной инфекции учёными разных стран проведены исследования направленные на изучение путей распространения и жизнеспособности вируса. Результаты исследования, проведённого в ФБУН ГНЦ ВБ «Вектор» Роспотребнадзора, по изучению жизнеспособности 
коронавируса SARS-CoV-2 в образцах дехлорированной питьевой воды при температуре 24 - $28{ }^{\circ} \mathrm{C}$ и $+4{ }^{\circ} \mathrm{C}$ в течение $1,3,24,48,72$ часов, а также в образцах, имитирующих морскую воду, с концентрацией солей по хлориду натрия 0,9 \% и 3,5 \% при температуре 24-28 ${ }^{\circ} \mathrm{C}$ в течение $1,3,24,48$ часов, свидетельствуют о том, что коронавирус SARS-CoV2 сохраняет остаточную инфекционную активность в дехлорированной питьевой воде в течение 72 часов, при этом степень его сохранности зависит от температуры воды. [8].

\section{Возможные пути передачи возбудителя COVID-19 через сточные воды,} загрязненные отходами антропогенного происхождения.

Исследования показали, что в 2-10\% подтвержденных случаев COVID-19 наблюдаются симптомы диареи в первый день госпитализации и сохраняются в течение нескольких дней после неё [9-11]. В фекалиях инфицированных пациентов выявлены фрагменты вирусной PHK SARS-CoV-2 [11-14]. Эти результаты показали, что косвенная передача заражённых фомитов (контаминированных предметов) также может играть решающую роль в распространении COVID-19 [15, 16].

В ряде зарубежных работ отмечено, что желудочно-кишечные симптомы, такие как диарея, диспепсия, вздутие живота и запоры в $10 \%$ случаев предшествуют респираторным симптомам и лихорадке $[10,17,16]$. Известны случаи, когда выздоровевшие пациенты все ещё давали положительный результат на наличие вирусной РНК в образцах стула [17-19].

Исследование китайских учёных[20], выявившее SARS-CoV-2 в образце стула у десятилетнего ребенка без симптомов заболевания, и обнаружение Wang W. et al. [21] живого коронавируса SARS-CoV-2 в образцах стула показало, что фекалии также могут являться материалом для диагностики на COVID-19 помимо образцов из дыхательных путей.

C вирусологической точки зрения, тропизм SARS-CoV-2 к оболочке кишечника является необычным, поскольку большинство вирусов, связанных с диареей (аденовирус, ротавирус, норовирус и т.д.) его не имеют. В исследовании, проведенном Xing и соавт. [22], тропизм SARS-CoV-2 к оболочке кишечника указывает на более высокую его устойчивость в кишечном тракте, чем у других вирусов.

Установлено, что SARS-CoV-2 использует рецепторы ACE2 для проникновения в организм хозяина $[23,24]$, и после этого множественные копии вирусной РНК и белков синтезируются в цитоплазме хозяина для сборки новых вирионов [25], которые затем могут быть выделены из желудочно-кишечного тракта. Фекалии 73-х госпитализированных пациентов с SARS-CoV-2 были протестированы методом ПЦР с обратной транскрипцией (rRT-PCR) в реальном времени. При исследовании образцов стула больных положительный результат дали 53,42\% от общего числа проб. Примечательно, что 23,29 \% пациентов с вирусной РНК, не выявленной в дыхательных путях, показали наличие SARS-CoV-2 в фекалиях [26]. Кроме того, в эпителии желудка, двенадцатиперстной и прямой кишки было выявлено положительное иммунофлуоресцентное окрашивание вирусного рецептора хозяина ACE2 (Ангиотензинпревращающий фермент 2) и вирусного нуклеокапсидного белка у пациентов с COVID-19. Исследователи смогли выделить SARS-CoV-2 из образцов кала, 
что указывает на наличие инфекционных вирионов в желудочно-кишечном тракте [27]. Эти результаты выявили возможность фекально-орального механизма передачи SARSCoV-2 $[19,28]$.

\section{Жизнестойкость возбудителя COVID-19 в сточных водах очистных сооружений канализации.}

Установки для очистки поверхностных вод наиболее подвержены вирусному загрязнению, что стало максимально актуальным во время вспышки COVID-19. Хотя в настоящее время нет достоверных данных о количестве жизнеспособных SARS-CoV-2, вызывающих заболевание при заглатывании воды во время купания.

В настоящее время для снижения вирусного загрязнения сточных вод применяют методы с использованием стресс-фактора, обусловленного воздействием солнечного света.

По данным польских и британских учёных, оценивших продолжительность жизни вируса в водоёмах при условии попадания в них сточных вод, а также риск инфицирования в случае контакта с заражённой водной системой, установлено, что коронавирус нового типа может выживать до 25 дней [29].

Существует практика использования на водоочистных сооружениях химического дозирования для образования активных окислительных частиц или фагирования другими микроорганизмами. В случае обычных централизованных водоочистных сооружений фильтрация с последующей дезинфекцией должна быть достаточной для избавления от SARS-CoV-2. Хотя слабая жизнеспособность SARS-CoV-2 в условиях открытого солнечного света снижает угрозу загрязнения сырой воды, применение хлорирования и УФ-дезинфекции создает гарантированную инактивацию SARS-CoV-2 до такой степени, что она представляет низкий риск для здоровья потребителя [30]. Кроме того, применение мер вторичной дезинфекции, таких как дозирование хлораминов для поддержания определенного уровня остаточного хлора в распределительной сети, даёт дополнительную защиту от загрязнения [30].

\section{Выделение вируса SARS-CoV-2 из речной воды.}

Ученые из Эквадора провели исследование речной воды города Кито [31]. Известно, что в Эквадоре лишь 20\% сточных вод охвачено очистными сооружениями [32], а его столица Кито, население которой составляет почти 3 миллиона человек, очищает только 3\% своих сточных вод (EPMAPS, 2020). Таким образом, река в г. Кито, получающая фекальные воды со всего города, сильно загрязнена микроорганизмами и другими загрязнителями, распространяя их вдоль бассейна реки [33]. В проведённых ранее исследованиях описано вирусное разнообразие патогенов человека, присутствующих в городской реке, и подчёркнут риск здоровью населения, которое может использовать эти воды для ирригационных или рекреационных целей [34]. Для оценки микробного влияния в речных водах использовали в качестве вирусного индикатора - человеческий аденовирус, что было связано с его частым обнаружением [35].

5 июня 2020 года были взяты пробы в трех точках реки г. Кито. Места отбора проб 
являлись репрезентативными для сбросов сточных вод в южном центре (M1), северном центре (M2) и севере (M3) в естественные потоки, проходящие через город. Параметры качества воды анализируемых образцов показали значительное антропогенное воздействие. Точки отбора проб М2 и М3 не соответствовали национальным требованиям по сохранению водной жизни для химической (ХПК) и биохимической (БПК) потребности в кислороде [36]. В трёх местах отбора проб SARS-CoV-2 ген белка нуклеокапсида $(\mathrm{N})$ присутствовал в концентрации в диапазоне от 2,91E+05 и 3,19E+06 GC/L для области-мишени N1 и от 2,07E+05 и 2,22E+06 GC/L для области-мишени N2. Более высокие значения отмечены в M1, что было связано со случаями COVID-19, зарегистрированными в зонах каждой точки. Сбор образцов происходил во время пика вспышки, поскольку активные случаи (считая выявленные случаи за последние 14 дней до дня отбора образцов) составили $25 \%$ от общего числа случаев COVID-19, зарегистрированных в городе с начала вспышки.

Это первое исследование, которое количественно оценило SARS-CoV-2 в речной воде, содержащей неочищенные сточные воды. Параметры воды, измеренные в 2-х из 3-х изученных мест, превосходили национальные нормативы по сохранению водной среды [37]. Однако все экологические значения превышали зарегистрированные для контрольных участков в этом же бассейне [38]. Вирусное загрязнение человеком, проанализированное с помощью индикатора $\mathrm{HAdV}$, показало большое влияние человеческих экскрементов на состояние воды в реке г. Кито. Значения были идентичны образцам, собранным в тех же местах в 2017 году, указывая на то, что санитарные условия не улучшились. В этом исследовании был проведён метагеномный анализ в тех же местах, и были получены последовательности из 26 вирусных патогенов человека, которые выявили последствия сброса сточных вод без предварительной обработки в естественные потоки.

На пике пандемии COVID-19 в Эквадоре уровни SARS-CoV-2, обнаруженные в реке г. Кито, аналогичны уровням загрязнения сточных вод Валенсии (Испания) с более 5000 активных случаев и сточных вод Парижа на пике эпидемии с более 10000 госпитализированных случаев [39]. Однако на дату отбора проб в городском участке реки Кито было зарегистрировано 750 активных случаев COVID-19, что свидетельствует, вероятно, о недостаточной диагностике, проводимой в других регионах мира. Кроме того, высокие значения могут быть связаны с большим количеством бессимптомных случаев. Так, на круизном судне «Алмазные принцы» бессимптомных случаев было 17,9\% [40], а в учреждении долгосрочного ухода у квалифицированных медсестер в округе Кинг, штат Вашингтон, 57\% случаев [41].

Важно отметить, что в водах был обнаружен только геномный материал, а жизнеспособность вируса в загрязненных водах неизвестна. Распространение вируса в окружающей среде оказывает неизвестное влияние на здоровье скота и диких животных, так как случаи зоонозных связей часто встречаются в семействе Coronaviridae [42,43]. Присутствие вируса в сбросах сточных вод в черте города может быть использовано эпидемиологической службой для контроля пандемии при дефиците диагностических средств [39]. Полученные данные соответствуют проведенным исследованиям в Нидерландах [44], Австралии [45], Италии [46], Испании [47] и Франции [48]. 
Согласно отчёту Национального Зелёного Трибунала (NGT) по стандартам сброса сточных вод очистных сооружений (последнее обновление 8 мая 2019 г.), в густонаселенных развивающихся странах дождь и таяние снега могут привести к ухудшению условий, вызывающих переливы канализации и приводящих к сбросам неочищенных сточных вод в водоёмы [49]. В общем исследовании по оценке риска здоровью был количественно определён риск инфицирования вследствие попадания в городские паводковые воды ряда патогенных микроорганизмов, таких как Campylobacter, Cryptosporidium, Giardia, норовирусы и энтеровирусы, которые могут вызывать желудочно-кишечные заболевания [50]. Отчёт показал, что в среднем риск заражения детей в местах, которые подвергаются воздействию паводковых вод, вытекающих из комбинированных сливов, ливневых канализационных и поверхностных стоков, образовавшихся в результате осадков, составил 33\%, 23\% и 3,5\% соответственно. Однако у взрослых соответствующий риск заражения составил 3,9\%, 0,58\% и 0,039\% соответственно, главным образом из-за норовирусов и энтеровирусов, присутствующих в паводковых водах [51].

Существует еще один риск, связанный с децентрализованными системами очистки сточных вод, такими как септические резервуары, поскольку такие системы вообще не дезинфицируют сточные воды. Следовательно, они могут загрязнять водоёмы с малой глубиной залегания грунтовых вод или в районах, подверженных затоплению, или если открытый колодец, используемый для питьевой воды, находится на расстоянии 30 м от септика, и не принимаются соответствующие меры предосторожности [51]. В случае таких ситуаций, как реагирование на стихийные бедствия, проект «Сфера» в 2011 году также рекомендовал минимальное стандартное боковое расстояние 30 м между санитарно-техническими сооружениями и источниками пресной воды [52].

C другой стороны, существует высокая вероятность распространения SARS-CoV-2 через аэрозоли, образующиеся на открытых аэробных очистных сооружениях, таких как в процессе с активным илом и т. д. [53]. В ходе исследования в 31 пробе воздуха различных станций очистки сточных вод (СОСВ) в течение двух сезонов два года подряд выявлялись три различных штамма вирусов: норовирус, аденовирус и вирус гепатита Е [54]. Аденовирус присутствовал почти во всех образцах (100\% летом и 97\% зимой), с самой высокой концентрацией в воздухе 2,27 × 106 эквивалента генома в м ${ }^{3}$. При этом норовирус обнаруживался редко, а вирус гепатита Е оставался незамеченным в образцах воздуха, полученных за определенный промежуток времени.

Таким образом, это исследование показало наличие потенциальных патогенных вирусных частиц в аэрозолях, выходящих из различных станций очистки сточных вод (COCВ). В связи с фактами заражения людей, работающих на канализационных очистных сооружениях (KOC) во время вспышки заболевания, вызванного SARS-CoV в 2002-2003 гг., и учитывая вероятность заражения специалистов, работающих с этими устройствами, в текущем ходе событий при пандемии COVID-19 было создано временное руководство ВОЗ «Вода, санитария, гигиена и управление отходами для вируса COVID-19» (март 2020 г.) [54].

Во время вспышки заболевания, вызванного SARS-CoV в 2003, сообщалось, что неисправные системы водопровода и вентиляции способствовали распространению 
SARS-CoV через аэрозоли в жилом комплексе Amoy Gardens Гонконга, где зафиксировано более 300 инфицирований с 42 летальными случаями $[55,56]$. Во время нынешней вспышки COVID-19 аналогичные заражения наблюдались у двух обитателей высотной башни под названием Hong Mei House на северо-западе Гонконга в Tsing Yi [56]. Зарегистрированные на юго-западе Дели 58 случаев заболевания COVID-19 подтверждают возможность заражения из-за неисправности системы водопровода при использовании общих туалетов пострадавшими лицами [57].

Следовательно, в случаях неисправности систем водопровода и вентиляции, особенно в высотных зданиях, следует учитывать возможность передачи COVID-19.

Заключение. Приведенный в статье анализ мировых научных исследований по теме новой коронавирусной инфекции позволил установить способность вируса выживать в водной среде урбанизированных территорий и осветить альтернативные пути распространения инфекционного агента в окружающей среде. Полученные сведения позволят разработать профилактические меры по сохранности санитарно-гигиенического состояния водных объектов и санитарно-защитных зон. Внедрение их в практику будет способствовать улучшению эпидемиологической ситуации в нашей стране.

\section{Список литературы:}

1. Summary table of SARS cases by country, 1 November $2002-7$ August 2003. Доступно по: https://www.who.int/csr/sars/coun- try/2003_08_15/en/. Ссылка активна на: 1 Сентября 2020.

2. Покровский В.И., Малеев В.В., Кисилев О.И. Коронавирус SARS является возбудителем SARS. Временное руководство [Коронавирус SARS - возбудитель атипичной пневмонии. Временные методические рекомендации. Москва, 2003. (на русском)

3. Чучалин А.Г. Синдром острого повреждения легких. РМЖ.2006; 14 (22): 1582.

4. Riley S., Fraser C., Donnelly C.A.,et al. Transmission dynamics of the etiological agent of SARS in Hong Kong: impact of public health interventions. Sci- ence, 2003;300(5627):1961-6. DOI: http://doi.org/10.1126/science.1086478

5. Lipsitch M., Cohen T., Cooper B.,et al. Transmission dynamics and control of severe acute respiratory syndrome. Science. 2003;300(5627): 1966-70. DOI: http://doi.org/10.1126/science.1086616

6. Surveillance case definitions for human infection with novel coro- navirus (nCoV). Доступно по: https://www.who.int/internal-publi- cations-detail/surveillance-case-definitionsfor-human-infection- withnovel-coronavirus-(ncov). Ссылка активна на: 1 Сентября 2020.

7. Disease commodity package - Novel Coronavirus (nCoV). Доступно по: https://www.who.int/publications-detail/disease-commodi- ty-package---novel-coronavirus(ncov),. Ссылка активна на: 1 Сентября 2020.

8. Золин В. В., Оськина О. П., Солодкий В. В., и др.Изучение жизнеспособности вируса SARS-CoV-2 в питьевой и морской воде. Covid19 - preprints.microbe.ru. Доступно по: https://doi.org/10.21055/preprints-3111723. Ссылка активна на: 1 Сентября 2020.

9. Cruvinel V.R.N, Marques C.P, Cardoso V., et al. Health conditions and occupational risks in a novel group: Waste pickers in the largest open garbage dump in Latin America. BMC Public Health. 2019; 581:16-19.

10. Chen N. et al. Epidemiological and clinical characteristics of 99 cases of 2019 novel 
coronavirus pneumonia in Wuhan, China: a descriptive study. Lancet. 2020; 395: 507-13.

11. Wang D. et al. Clinical characteristics of 138 hospitalized patients with 2019 Novel Coronavirus-Infected Pneumonia in Wuhan, China. JAMA - J. Am. Med.Assoc.2020;323:10611069.

12. Wölfel R. et al. Virological assessment of hospitalized patients with COVID2019.Nature. 2020;581:465-469.

13. Huang C. et al. Clinical features of patients infected with 2019 novel coronavirus in Wuhan, China. Lancet.2020; 395:497-506.

14. Holshue M. L. et al. First case of 2019 Novel Coronavirus in the United States. N. Engl. J. Med. 2020;382:929-936.

15. Zhou P. et al. A pneumonia outbreak associated with a new coronavirus of probable bat origin. Nature. 2020;579:270-273.

16. Mallapaty S. How sewage could reveal true scale of coronavirus outbreak. Nature.2020; 580:176-177.

17. Lesté-Lasserre C. Coronavirus found in Paris sewage points to early warning system. Science. Доступно по:https://doi.org/10.1126/science.abc3799. Ссылка активна на: 1 Сентября 2020.

18. Gu J., Han B., Wang J. COVID-19: gastrointestinal manifestations and potential fecal-oral transmission. Gastroenterology.2020;158:1518-1519.

19. Kam K. et al. A well infant with coronavirus disease 2019 with high viral load. Clin. Infect. Dis. Доступно по: https://doi.org/10.1093/cid/ciaa201. Ссылка активна на: 1 Сентября 2020.

20. Ling Y. et al. Persistence and clearance of viral RNA in 2019 novel coronavirus disease rehabilitation patients. Chin. Med. J. (Engl.). 2020;133:1039-1043.

21. Wang W. et al. Detection of SARS-CoV-2 in different types of clinical specimens. JAMA - J. Am. Med. Assoc.2020; 323:1843-1844.

22. Tang A. et al. Detection of Novel Coronavirus by RT-PCR in stool specimen from asymptomatic child, China. Emerg. Infect. Dis.2020;26:1337-1339.

23. $\mathrm{Xu} \mathrm{Y}$. et al. Characteristics of pediatric SARS-CoV-2 infection and potential evidence for persistent fecal viral shedding. Nat. Med. 2020;26:502-505.

24. Xing Y.-H. et al. Prolonged viral shedding in feces of pediatric patients with Coronavirus Disease 2019. J. Microbiol. Immunol. Infect. DOI: https://doi.org/10.1016/j.jmii.2020.03.021.

25. Munster V. J., Koopmans M., van Doremalen N., et al.. A novel coronavirus emerging in China—key questions for impact assessment. N. Engl. J. Med.2020; 382:692-694.

26. Harmer D., Gilbert M., Borman R., et al. Quantitative mRNA expression profiling of ACE 2, a novel homologue of angiotensin converting enzyme. FEBS Lett. 2002;532:107-110.

27. Weiss S. R., Navas-Martin S. Coronavirus pathogenesis and the emerging pathogen severe acute respiratory syndrome Coronavirus. Microbiol. Mol. Biol.Rev.2005; 69:635-664.

28. Organization (WHO), W. H. Water, sanitation, hygiene, and waste management for the COVID-19 virus. Доступно по:https://apps.who.int/iris/bitstream/handle/10665/331499/ WHO-2019-nCoV-IPC_WASH-2020.2-eng.pdf?sequence=1\&isAllowed=y. Ссылка активна на: 1 Сентября 2020. 
29. Jamie Shutler, Krzysztof Zaraska, Thomas M. Holding, et al. Ravinder Dahiya Risk of SARS-CoV-2 infection from contaminated water systems. DOI:

https://doi.org/10.1101/2020.06.17.20133504

30. Li R. A., McDonald J. A., Sathasivan A., et al. Disinfectant residual stability leading to disinfectant decay and by-product formation in drinking water distribution systems: a systematic review. Water Res.2019; 153:335-348.

31. Guerrero-Latorre L., Ballesteros I., Villacrés I. M., et al. SARS-CoV-2 in river water: Implications in low sanitation countries. Science of The Total Environment. DOI: 10.1016/j.scitotenv.2020.140832

32. Rodriguez Hector, Alexander Delgado, Anna Nolasco, et al.. From Waste to Resource. Water Papers. World Bank. DOI: https://doi.org/doi:10.1596/33436

33. Voloshenko-Rossin A., Gasser G., Cohen K., et al. Emerging pollutants in the Esmeraldas watershed in Ecuador: discharge and attenuation of emerging organic pollutants along the San Pedro-Guayllabamba-Esmeraldas rivers. Environ. Sci. Process. Impacts.2015;17, 41-53. DOI: https://doi.org/10.1039/C4EM00394B

34. Guerrero-Latorre L., Romero B., Bonifaz E., et al. Quito's virome: Metagenomic analysis of viral diversity in urban streams of Ecuador's capital city. Sci Total Environ.2018;645:1334 - 1343.DOI: https://doi.org/10.1016/j.scitotenv.2018.07.213

35. Ministerio del Ambiente de Ecuador. 097-A Refórmese el Texto Unificado de Legislación Secundaria. Registro Oficial. Año III - No 387.Quito, miércoles 4 de noviembre de 2015;78:6.

36. Rusiñol M., Fernandez-Cassi X., Hundesa,A., et al. Application of human and animal viral microbial source tracking tools in fresh and marine waters from five different geographical areas. Water Research. 2014; 59: 119-129. DOI:https://doi.org/doi:10.1016/j.watres.2014.04.013

37. Ríos-Touma B., Acosta R., Prat N. The Andean biotic index (ABI): Revised tolerance to pollution values for macroinvertebrate families and index performance evaluation. Rev. Biol. Trop.2014; 62:249-273.

38. Randazzo W., Cuevas-Ferrando E., Sanjuan R., et al. Metropolitan Wastewater Analysis for COVID-19 Epidemiological Surveillance. Med Rxiv. 2020;4:23. DOI: https://doi.org/10.1101/2020.04.23.20076679

39. Wurtzer S., Marechal V., Mouchel J.M., et al. Evaluation of lockdown impact on SARS-CoV-2 dynamics through viral genome quantification in Paris wastewaters. medRxiv 2020.04.12.20062679; DOI: https://doi.org/10.1101/2020.04.12.20062679

40. Mizumoto K., Kagaya K., Zarebski A., et al. Estimating the asymptomatic proportion of coronavirus disease 2019 (COVID-19) cases on board the Diamond Princess cruise ship, Yokohama, Japan, Eurosurveillance,2020;25:1-5.

DOI:10.2807/1560- 7917.ES.2020.25.10.2000180

41. Kimball A., Hatfield K. M., Arons M., et al. Asymptomatic and Presymptomatic SARS-CoV-2 Infections in Residents of a Long-Term Care Skilled Nursing Facility - King County, Washington, March 2020. MMWR. Morbidity and mortality weekly report.2020; 69(13):377-381. DOI: https://doi.org/10.15585/mmwr.mm6913e

42. Bivins A., North D., Ahmad A., et al. Wastewater- Based Epidemiology: Global Collaborative to Maximize Contributions in the Fight Against COVID-19. Environ. Sci. 
Technol. DOI: https://doi.org/10.1021/acs.est.0c02388

43. Franklin A. B., Bevins S. N. Spillover of SARS-CoV-2 into novel wild hosts in North America: A conceptual model for perpetuation of the pathogen. The Science of the total environment, 733, 139358. Advance online publication. DOI: https://doi.org/10.1016/j.scitotenv.2020.139358

44. Medema G., Heijnen L., Elsinga G., et al. Presence of SARSCoronavirus-2 RNA in Sewage and Correlation with Reported COVID-19 Prevalence in the Early Stage of the Epidemic in The Netherlands. Environ. Sci. Technol. Lett. A-F. DOI: https://doi.org/10.1021/acs.estlett.0c00357 (2020).

45. Ahmed,W. et al. First confirmed detection of SARS-CoV-2 in untreated wastewater in Australia: a proof of concept for the wastewater surveillance of COVID-19 in the community. Sci. Total Environ. 2020;728.

46. La Rosa, G. et al. First detection of SARS-CoV-2 in untreated wastewaters in Italy. Sci. Total Environ.2020; 736.

47. Randazzo W., Cuevas-Ferrando E., Sanjuan R., et al. Metropolitan wastewater analysis for COVID-19 epidemiological surveillance. DOI: https://doi.org/10.1101/2020.04.23.20076679v2.

48. Wurtzer S., Marechal V., Mouchel J.-M., et al. Time course quantitative detection of SARS-CoV-2 in Parisian wastewaters correlates with COVID-19 confirmed cases. DOI: https://doi.org/10.1101/2020.04.12.20062679v1.full.pdf .

49. Tibbetts J. Combined sewer systems: down, dirty, and out of date. Environ. Health Perspect.2005; 113: 465-467.

50. De Man H. et al. Quantitative assessment of infection risk from exposure to waterborne pathogens in urban floodwater. Water Res.2014; 48: 90-99.

51. Banks D., Karnachuk O. V., Parnachev V. P., et al. B. Groundwater contamination from rural pit latrines: examples from Siberia and Kosova. J. Chart. Inst. Water Environ. Manag.2002; 16:147-152.

52. The Sphere Project \& The Sphere Project. 4. Minimum Standards in Water Supply, Sanitation and Hygiene Promotion. in Humanitarian Charter and Minimum Standards in Humanitarian Response. DOI: https://doi.org/10.3362/9781908176202.004 (2011).

53. Masclaux F. G., Hotz P., Gashi D., et al. Assessment of airborne virus contamination in wastewater treatment plants. Environ. Res. 2014;133:260-265.

54. Wigginton K. R., Ye Y., Ellenberg R. M. Emerging investigators series: The source and fate of pandemic viruses in the urban water cycle. Environ. Sci.: Water Res. Technol.2015; 1: 735-746.

55. Yu I. T. S., Qiu H., Tse L. A. et al. Severe acute respiratory syndrome beyond amoy gardens: completing the incomplete legacy. Clin. Infect. Dis. 2014;58: 683-686.

56. Regan H. How can the coronavirus spread through bathroom pipes? Experts are investigating in Hong Kong. CNN. Доступно по: https://edition.cnn.com/2020/02/12/asia/hongkong-coronavirus-pipes-intlhnk/index.html. Ссылка активна на : 1 Сентября 2020.

57. Press Trust of India. Kapashera hot spot: No space for social-distancing in cramped rooms, common toilets. INDIA TODAY. https://www.indiatoday.in/india/ story/kapashera-hot- 
spot-no-space-for-social-distancing-in-cramped-roomscommon(2020). toilets-1673968-2020-05-03 